\title{
Performance of Hot Asphalt Mixtures Containing Plastic Bottles as Additive
}

\author{
Hakeem Jan ${ }^{1, *}$, Mohamad Yusri Aman ${ }^{2}$, Sheraz $\mathrm{Khan}^{3}$, and Fazal Karim ${ }^{4}$ \\ ${ }^{1,2}$ Faculty of Civil and Environmental Engineering, Universiti Tun Hussein Onn Malaysia, 86400 \\ Parit Raja, Johor, Malaysia \\ ${ }^{3,4}$ Faculty of Civil Engineering, SUIT, 25000 Peshawar Pakistan
}

\begin{abstract}
This study focuses on evaluating the resistance of polymer modified asphalt mixes and the role played by asphalt in the realm of construction is undeniably important. Addition of polymers $(\mathrm{PB})$ as additives to asphalt helps to improve the strength and water repellent property of the mix and as well as helps environment in various ways and at the same time, analyzing its lower maintenance activities and service life is most important. The use of inexpensive polymers, in this case, waste polymers has without any doubt proven to be the most convenient way of reducing the cost of construction and at the same time maintaining quality. The main resolve for this research was to establish the effects of the use of plastic bottles on hot asphalt and its mixtures. In order to put this into perspective, varying percentages of asphalt mixtures were calculated and subjected to laboratory tests. The two-factor variance analysis (ANOVA) was conducted to determine the significance at various confidence limits. The results indicate that the inclusion of Polyethylene Terephthalate (PET) had a particularly substantial effect on the properties of asphalt. Consequently, it can encourage the re-utilization of waste in the manufacturing industry in an ecologically friendly and cost-effective way.
\end{abstract}

\section{Introduction}

Asphalt is the product of a mixture of binders, aggregates and filler. It is used both for construction and maintenance of the road, pavements and sometimes even parking areas. Polyethylene Terephthalate is a non-biodegradable, polymer. It is half-crystalline thermoplastic in nature. For this reason, it is considered to be a polyester material. It forms the greater percentage of most plastic wastes in any modern municipality. Plastics are famous the world over. Large volumes of waste polyethylene terephthalate are manufactured mostly by European nations. They come in various shapes and forms including, molding, bottles, fibers as well as sheets. Polyethylene Terephthalate comes in handy in the food industry thanks to its superlative nature. Bottles and cans are used as packaging containers. However, Extensive generation of wastes would bring disastrous effects to the ecosystem especially when disposed of in landfills.

* Corresponding author: khyberpass08@gmail.org 
According to [1], asphalt mixtures' service life has been on the decrease over the last decade. They attribute this decline in quality and longevity to the considerable increase in the number of heavy vehicle on roads. The most affected types of vehicles are vans and trucks. In addition to that, the performance of asphalt is influenced by the atmospheric temperature. The reason for this behavior is because asphalt is visco-elastic in nature [1]. For this is a reason, it is greatly affected by fluctuations in temperature. Naturally, high temperatures induce softer or fewer viscose binders which in turn affect the asphalt's performance in a negative way.

In order to avoid these complications and come up with a better mixture that has a prolonged service life, most road engineers have resorted to modifying asphalt mixtures. They achieve this feat by using additives namely; polymers and fibers.In their investigation, [2] also confirms that the modification of asphalt using polymers provides a vital stance upon which the designing of a flexible pavement is inclined. Majorly, this contributes towards increasing the pavements service length or reducing its layer or the thickness of its base.

What is more, it has been found that polymers affect bitumen. Not only does it increase the stiffness of asphalt, but it also ensures enhanced temperature vulnerability. [3] posits that increased stiffness guarantees better altered rutting resistance in hot weather. Additionally, they suggest that bitumen can be relatively used with a softer base with a view to achieving better results during cool temperatures. It is also revealed that polymers possess better bonding agents along with interconnected properties. Polymers also act as an additive for asphalt concrete mixtures [4]. Consequently, it serves as an aggregate material majorly used for coating. These kinds of coatings enhance the toughness of an aggregate surface. In this way, superior engineering properties in the production of the mixtures of asphalt are guaranteed.

There exist a number of polymers that are often used in the modification of bitumen. They are subdivided into a couple of groups following their behaviors when subjected to heat [4]. These groups include; thermosetting and thermoplastic polymers. On one hand, thermosetting polymers, that is elastomers and resins are cured by the use of heat in order to produce a three-dimensional structure bearing crosslinking bonds which offer due resistance to polymers matrix tempering. On the other hand, thermoplastic polymers are susceptible to heat; hence their shapes can be easily altered and redesigned into other forms. [4], confirms that the significant difference between the two is that the latter is reversible while the former is irreversible. As it seems, pavement defects such as rutting in high temperatures, cracking in areas experiencing low temperatures and so on, are as a result of vehicle loading and perhaps most importantly asphalt concrete's inability to resist changes in temperature.

Scientists and researchers the world over have put themselves to task to explore the recycling of waste material to the advantage of the environment as well as the economy. Most importantly they attempt to look into the possibility of the re-use of solid waste material in the construction of roads. According to [2] the best way to get rid of the excessive solid waste accumulating urban and industrial areas is to implement the re-use of waste material. This initiative would have a significant impact on both the environment and the economy in some ways.

To begin with, it would help in reducing the over-reliance on natural resources saving them from exhaustion in the process. Secondly, it would keep environmental pollution by wastes generated from urban and industrial areas in check. Thirdly, it helps in saving money as well as energy [2]. Generally, in this plastic study bottle which is in the actual sense a form of polyethylene terephthalate as an asphalt mixture additive was investigated. The study evaluates the performance of hot asphalt by using plastic bottles as additives [3]. 


\section{Materials and methodology}

In this experiment, polyethylene was used in the modification of asphalt mixtures. Black gravels were collected and pulverized into rough aggregate for performance evaluation of polyethylene on hot asphalt mixtures. The resultant fine dust was used as a filler material. It was acquired from the aggregate mixture of Domar. As the stone was being crushed, a large amount of dust was produced. Some of it was trapped in the pulverized rock. The dust was eventually mixed with the sand in a bid to make certain the maximum utilization of stone dust.

This experiment incorporated the use of domestic waste as well as low-density bags polyethylene bags. After cleaning the waste polyethylene, they were eventually shredded into tiny particles of 2-3 $\mathrm{mm}$ for the preparation of recycled polyethylene. [5] recommended a gravity of 0.94 and a melting temperature of $115^{\circ} \mathrm{C}$. These conditions were imperative for the preparation of the polyethylene. It would enhance the acquisition of better results.

As dictated by AASHTO, samples of bitumen were tested to assess different properties of asphalt, commonly referred to as fire and flash points, softening points as well as penetration value [6]. Mainly, the properties of bitumen binder were maintained within the penetrating specification of asphalt grade 80/100. Specimens of bitumen were then prepared for evaluating the Marshall stability which is concomitant with the mixtures of asphalt and waste polyethylene. These preparations were guided by test formula by Bruce Marshall that was improved by the Engineer Corps of the United States [4].

Aggregates of approximately $1200 \mathrm{~g}$ were for that reason used in the preparation of this specimen which was $101.6 \mathrm{~mm}$ in diameter with the breadth of around $63.5 \mathrm{~mm}$ of unadulterated bitumen. Moreover, the average amount of bitumen relevant in the preparation of the mixture was ascertained by this method [7]. It is equally imperative to note that the Marshall Stability was utilized in the prediction of the performance degree of stability of the mixture, the capacity of weight carrying as well as the permanent deformation resistance. The same goes for the flow test. A total of nine samples were used in the process of determining the content of optimum asphalt binder with different proportions of road [7].

The already crushed black stone was further, manually broken down into $25.00 \mathrm{~mm}$ downgraded pieces. As dictated by [5], the rough aggregate needed to be sieved of using a $2.36 \mathrm{~mm}$ sieve. As a result, a superlative aggregate that would pass through $2.36 \mathrm{~mm}$ but is retained by a sieve of $0.075 \mathrm{~mm}$ was obtained from the coarse aggregate sand. It is recommended that a non-plastic sieve of not more than $0.075 \mathrm{~mm}$ should be used to meet the mineral filler's requirements. According to the authors, a constantly graded bituminous aggregate is essential in the evaluation of the asphalt concrete mix that is improved using additives on behavior. On the other hand, the latter needs even aggregate assortment gradation for it to attain a dense mix with a free-air controlled ideal content for the construction of steady as well as long-lasting supple pavement.

\section{Results}

This investigation evaluated the performance of hot asphalt with regards to flash, fire, bitumen penetration as well as softening points. Samples of different ground polymers (plastics) were mixed with asphalt. The results that were obtained were presented in details in the subsequent section. The results revealed an inverse variation in the comparison of polymer added in bitumen and the value of penetration. The highest possible value of penetration of 85 was achieved with the addition of a polymer of $0 \%$ whereas; the lowest penetration value of zero was obtained with the addition of a polymer of $16 \%$. Other results 
received included; penetration value of 70 with an addition of a polymer of $2 \%$, penetration value of 64 with an addition of a polymer of 4\%, penetration value of 57 with an addition of a polymer of $6 \%$, penetration value of 46 with an addition of a polymer of $8 \%$, penetration value of 38 with an addition of a polymer of $10 \%$, penetration value of 24 with an addition of a polymer of $12 \%$, penetration value of 13 with an addition of a polymer of $14 \%$.

Table 1. Comparison between polymer added (\%) and penetration value.

\begin{tabular}{|c|c|}
\hline Polymer added in Bitumen (\%) & Penetration Value \\
\hline 0 & 85 \\
\hline 2 & 70 \\
\hline 4 & 64 \\
\hline 6 & 57 \\
\hline 8 & 46 \\
\hline 10 & 38 \\
\hline 12 & 24 \\
\hline 14 & 13 \\
\hline 16 & 0 \\
\hline
\end{tabular}

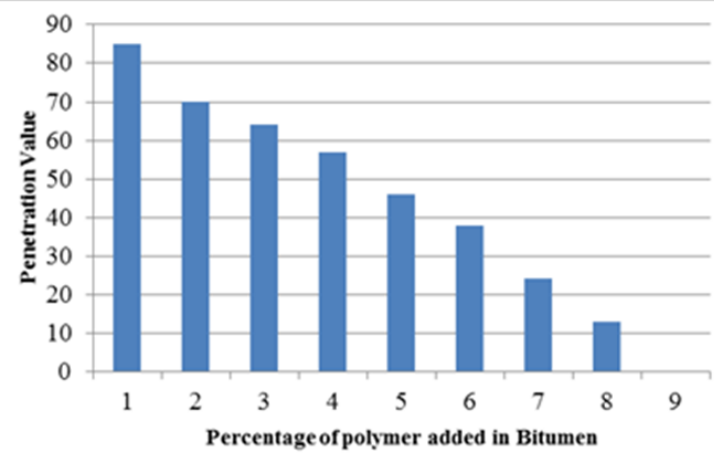

Fig. 1. Comparison between polymers added (\%) and penetration value.

When comparing the additional polymer and their resultant points of softening, the research revealed that these factors were directly interrelated with one other. For instance, zero percent unadulterated Bitumen, had a corresponding softening point of $55 \mathrm{C}^{\mathrm{o}}$, Bitumen $57 \mathrm{C}^{\mathrm{o}}$ with polymer of $1 \%$, Bitumen at $61 \mathrm{C}^{\circ}$ with polymer of $2 \%$, Bitumen at $65 \mathrm{C}^{\mathrm{o}}$ with polymer of $3 \%$ and finally bitumen at $68 \mathrm{C}^{\circ}$ with polymer of $4 \%$ (Table and Figure 2). The mean softening point was thus found to $\mathrm{be} \pm \mathrm{SD}=27.980$ and Std. Error $=9.327$.

Table 2. Comparison between Polymers added (\%) and Softening Point.

\begin{tabular}{|c|c|}
\hline Polymer added in Bitumen (\%) & Softening Point $\left(\mathrm{C}^{\circ}\right)$ \\
\hline 0 & 55 \\
\hline 1 & 57 \\
\hline 2 & 61 \\
\hline 3 & 65 \\
\hline 4 & 68 \\
\hline
\end{tabular}




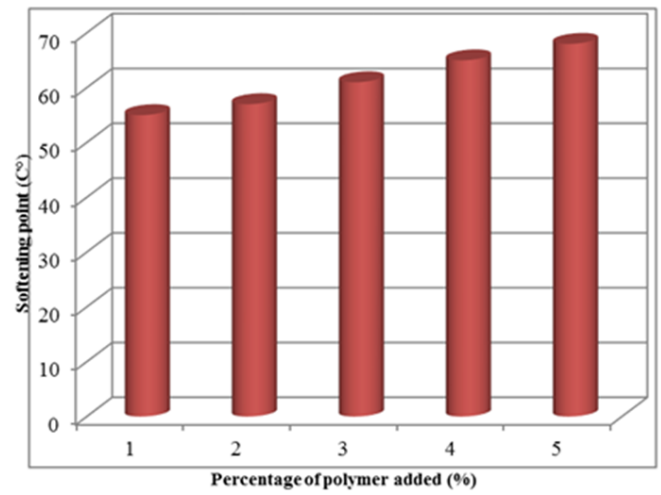

Fig. 2. Comparison between Polymers added (\%) and Softening Point.

When comparing the various percentages of fire point, flash point, and plastics added, the outcomes revealed that unadulterated bitumen possessed flash and fire points of $246 \mathrm{C}^{\circ}$ and $238 \mathrm{C}^{\circ}$ respectively. The flash and fire points were $252 \mathrm{C}^{\circ}$ and $241 \mathrm{C}^{\circ}$ for an additional polymer of $1 \%$, while the flash and fire points were $278 \mathrm{C}^{\circ}$ and $268 \mathrm{C}^{\circ}$ for an additional polymer of $1 \%$ respectively. The mean flash point was $260.8 \pm \mathrm{SD}=11.649$ and Std. Error $=5.210$. Additionally, mean fire point was $250.8 \pm \mathrm{SD}=12.194$ and Std. Error $=5.453$. (Table and Fig. 3).

Table 3. Percentage of polymer added, fire point and flash point

\begin{tabular}{|c|c|c|}
\hline Polymer added in Bitumen (\%) & Fire point $\left(\mathrm{C}^{\circ}\right)$ & Flash Point $\left(\mathrm{C}^{\circ}\right)$ \\
\hline 0 & 238 & 246 \\
\hline 1 & 241 & 252 \\
\hline 2 & 250 & 263 \\
\hline 3 & 257 & 269 \\
\hline 4 & 268 & 274 \\
\hline
\end{tabular}

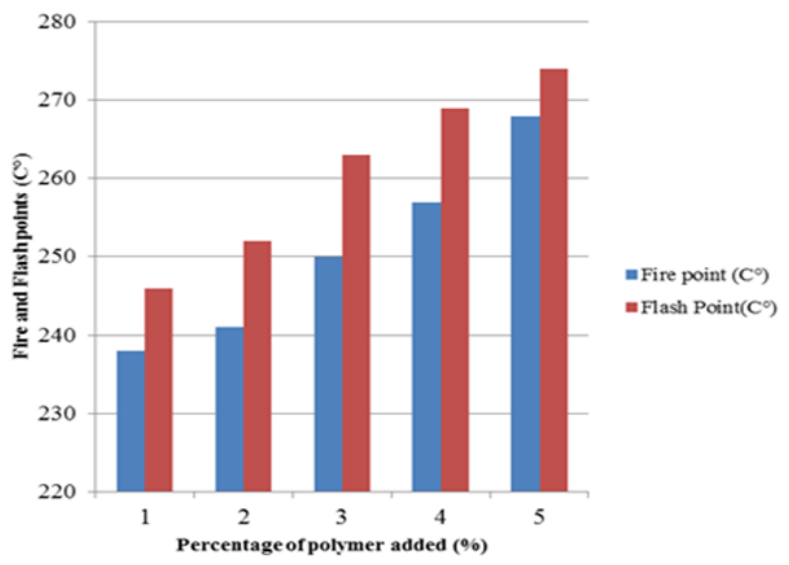

Fig. 3. Percentage of polymer added, fire point and flash point 


\section{Discussions}

Bitumen is often used in constructing supple pavements by tying the aggregates together by way of layering the aggregates. Moreover, the material endorses the high point as well as the life service of the pavement. On the other hand, following its poor characteristics, for instance, its resistance to water, bitumen is universally bettered through the modification of its properties of rheology by mixing it with artificial polymers, for example, rubber and plastics [7]. Since the use of waste plastic with bitumen is similar to using polymer modified bitumen, this test used discarded plastic to assess the performance of hot asphalt with regards to flash, fire, bitumen penetration as well as softening points.

This research established a marked decline in the penetration value with the subsequent increase in the content of polymer Bitumen. This without any doubt suggests the necessity for a tougher modifying binder. These results are in favor of what was reported until this time by [8] which posited that the standards of penetration flexibility and enhanced bitumen lessened with the increase in the content of plastic up to $12 \%$ in weight. In different study carried out by [9], performance appraisal of bitumen mixtures, (15\%) bitumen and (8\%) plastic were likened to a blend of typical bituminous concrete. The outcomes showed enhanced properties, for example, retained immovability to incidental ductile strength and rutting with polymer modified bitumen concrete. The authors maintained that the modified mixtures are impervious to lasting deformation in raised temperatures.

Moreover, the plastics that are used in the process of bitumen modification can as well be classified into the above groups. The most commonly used thermoplastic polyester is referred to as polyethylene terephthalate (PET). As stated earlier in the paper it is also known as 'polyester' [1]. It hardly goes without noticing that the name - polyester - causes mix-up due to the similarities it shares with polyester resins which belong to the group of thermosetting polymers. By and large, polyethylene terephthalate could be labeled as a crystal clear polymer with a decent perfunctory property as well as dimensional constancy in dissimilar load. According to [2], this polymer boasts of good barrier properties on gas as well as excellent resistance to chemicals. This characteristic offers an explanation for its prevalent use in the making of bottles, electrical components, and thermally stabilized films and in the manufacturing of textile.

According to [5], there has been a general increase in the use of asphalt in the construction of road pavements, especially in binding aggregates. Even so, the main disadvantage is that the asphalt coating stratum is always vulnerable to adverse temperatures [6]. It experiences rutting during high temperatures, fatigue during medium temperatures and cracking during low temperatures. This validates the act of modifying asphalt mixtures with a view to ensuring enhanced application. Improved road properties may be realized through the use of apposite starting rudimentary oil while making individual meticulous refinery process [1]. However, in both cases, it is quite challenging to realize.

\section{Conclusion}

This experiment revealed that discarded plastic materials could be used effectively in the modification bitumen for the construction of ductile pavements. It is easily achieved through the process of mixing treated waste plastic of different quantities by weight of asphalt to in a bid to guarantee considerable enhancement in the Marshall stability, strength, as well as other associated characteristics of the improved bituminous concrete with a view to attain durability and improved performance of roads and pavements with negligible bitumen utility. Furthermore, the procedure is kind to the surroundings. Nonetheless, this 
investigation vouches for additional studies in order to establish the precise quantities of the mixtures that provide the best results.

\section{References}

[1] T.B. Moghaddam, M. Soltani and M.R. Karim, Evaluation of permanent deformation characteristics of unmodified and Polyethylene Terephthalate modified asphalt mixtures using dynamic creep test, Materials \& Design, 53, 317-324 (2014)

[2] E. Ahmadinia, M. Zargar, M.R. Karim, M. Abdelaziz and P. Shafigh, Using waste plastic bottles as additive for stone mastic asphalt, Materials \& Design, 32(10), 48444849 (2011)

[3] M.T. Awwad and L. Shbeeb, The use of polyethylene in hot asphalt mixtures, American Journal of Applied Sciences, 4(6), 390-396 (2007)

[4] A. Gawande, G.S. Zamre, V.C. Renge, G.R. Harsakale and S. Tayde, Utilization of waste plastic in asphalting of roads a review, Sci. Revs. Chem. Commun., 2(2), 147-157 (2012)

[5] M.N. Rahman, M. Ahmeduzzaman, M.A. Sobhan and T.U. Ahmed. Performance evaluation of waste polyethylene and pvc on hot asphalt mixtures, American J. of Civil Engineering and Architecture, 1(5), 97-102 (2013)

[6] A. Jamshid, M.O. Hamzah and Z. You, Performance of warm mix asphalt containing Sasobit $\AA$ : State-of-the-art, Construction and Building Materials, 38, 530-553 (2013)

[7] G. Sarang, B.M. Lekha, G. Krishna and A.U.R. Shankar, comparison of stone matrix asphalt mixtures with polymer-modified bitumen and shredded waste plastics, Road Materials and Pavement Design, 1-13, (2015)

[8] C.E.G. Justo and A. Veeraragavan, Utilization of waste plastic bags in bituminous mix for improved performance of roads, Centre for Transportation Engineering, Bangalore University, Bangalore, India, (2002)

[9] S. Rashid, T.A. Khan, Sangita, D.K. Sharma, Performance evaluation of waste plastic/polymer modified bituminous concrete mixes, Journal of Scientific and Industrial Research, 68(11), 975-979 (2009) 